\title{
MiR-100 regulates cell differentiation and survival by targeting RBSP3, a phosphatase-like tumor suppressor in acute myeloid leukemia
}

\author{
Y-S Zheng ${ }^{1,2,5}$, H Zhang ${ }^{1,5}$, X-J Zhang ${ }^{1}$, D-D Feng ${ }^{1}$, X-Q Luo ${ }^{3}$, C-W Zeng ${ }^{1}$, K-Y Lin ${ }^{1}$, H Zhou ${ }^{1}$, \\ L-H Qu ${ }^{1}, \mathrm{P}$ Zhang $^{4}$ and Y-Q Chen ${ }^{1}$
}

${ }^{1}$ Key Laboratory of Gene Engineering of the Ministry of Education, State Key Laboratory for Biocontrol, Sun Yat-sen University, Guangzhou, China; ${ }^{2}$ Department of Biotechnology, Hainan University, Hainan, China; ${ }^{3}$ The First Affiliated Hospital of Sun Yat-sen University, Guangzhou, China and ${ }^{4}$ Institute of Pathology and Southwest Cancer Center, Southwest Hospital, Third Military Medical University, Chongqing, China

Acute myeloblastic leukemia (AML) is characterized by the accumulation of abnormal myeloblasts (mainly granulocyte or monocyte precursors) in the bone marrow and blood. Though great progress has been made for improvement in clinical treatment during the past decades, only minority with AML achieve long-term survival. Therefore, further understanding mechanisms of leukemogenesis and exploring novel therapeutic strategies are still crucial for improving disease outcome. MicroRNA100 (miR-100), a small non-coding RNA molecule, has been reported as a frequent event aberrantly expressed in patients with AML; however, the molecular basis for this phenotype and the statuses of its downstream targets have not yet been elucidated. In the present study, we found that the expression level of miR-100 in vivo was related to the stage of the maturation block underlying the subtypes of myeloid leukemia. In vitro experiments further demonstrated that miR-100 was required to promote the cell proliferation of promyelocytic blasts and arrest them differentiated to granulocyte/monocyte lineages. Significantly, we identified RBSP3, a phosphatase-like tumor suppressor, as a bona fide target of $\mathrm{miR}-100$ and validated that RBSP3 was involved in cell differentiation and survival in AML. Moreover, we revealed a new pathway that miR-100 regulates G1/S transition and S-phase entry and blocks the terminal differentiation by targeting RBSP3, which partly in turn modulates the cell cycle effectors pRB/E2F1 in AML. These events promoted cell proliferation and blocked granulocyte/monocyte differentiation. Our data highlight an important role of miR-100 in the molecular etiology of AML, and implicate the potential application of miR-100 in cancer therapy.

Oncogene (2012) 31, 80-92; doi:10.1038/onc.2011.208; published online 6 June 2011

Correspondence: Professor Y-Q Chen, Key Laboratory of Gene Engineering of the Ministry of Education, Biotechnology Research Center, Sun Yat-sen University, Guangzhou 510275, PR China.

E-mail: 1sscyq@mail.sysu.edu.cn

${ }^{5}$ These authors contributed equally to this work.

Received 22 November 2010; revised 19 March 2011; accepted 5 April 2011; published online 6 June 2011
Keywords: microRNA; acute myeloblastic leukemia; granulocyte/monocyte differentiation; RBSP3-pRBE2F1 pathway

\section{Introduction}

Acute myeloblastic leukemia (AML) arises from the differentiation arrest of myeloid precursor and malignant proliferation in the bone marrow (BM) and blood. It can be divided into different subtypes based on the cell type and the degree of maturity (Lowenberg et al., 1999). Although much progress has been achieved in the clinical treatment of AML in recent decades, only approximately $40 \%$ of patients with AML achieve longterm survival (Farag et al., 2005; Estey and Döhner, 2006; Estey, 2007). Therefore, a better understanding of the mechanisms responsible for leukemogenesis and an exploration of novel therapeutic strategies are crucial for achieving an improved outcome.

The differentiation of AML lineages is regulated by a dynamic interaction between lineage-specific regulators, including microRNAs (miRNAs), which have key roles in hematopoiesis (Chen, 2005; Fontana et al., 2007; Jongen-Lavrencic et al., 2008; Han et al., 2010). MiRNAs, a novel class of small non-coding RNAs that range from 19 to 25 nucleotides in length, can silence specific target genes through translational repression or direct mRNA degradation (Bartel, 2004; Lim et al., 2005). The deregulated expression of specific miRNAs that modulate the expression of oncogenes and tumor suppressors is associated with the development of malignancies (Chen, 2005; Esquela-Kerscher and Slack, 2006). Currently, several miRNAs have been reported as oncogenes or tumor suppressors in leukemia (Fazi et al., 2005; Fontana et al., 2007; Bousquet et al., 2008; Garzon et al., 2009; Pigazzi et al., 2009; Han et al., 2010; Liu et al., 2010). A few reports have described miRNA expression that is highly regulated according to the developmental lineage of the cell and restricted miRNA expression profiles during hematopoiesis. For example, miR-125b-1 arrests myeloid cell differentiation in myelodysplastic syndrome (MDS) and in AML 
(Bousquet et al., 2008), and miR-223 regulates the differentiation of human granulopoiesis (Fazi et al., 2005). MiR-424 stimulates monocyte differentiation via the translational repression of NFI-A (Rosa et al., 2007), and a restricted miRNA signature distinguishes APL blasts from normal promyelocytes (Careccia et al. 2009). However, the functions of other miRNAs in leukemia have been minimally explored.

MiR-100 is aberrantly expressed in a number of cancer cells, including AML cells with a $\mathrm{t}(15 ; 17)$ (Jongen-Lavrencic et al., 2008; Li et al., 2008; Varnholt et al., 2008; Leite et al., 2009). A few studies have also reported that miR-100 regulates the expression of Polo-like kinase 1 in nasopharyngeal cancer, whereas it targets mTOR in adrenocortical cancer cells and in clear cell ovarian cancer (Nagaraja et al., 2010; Shi et al., 2010). These results suggest that miR-100 might function as a tumor suppressor or as an oncogene in different cancers. We have previously found that miR100 is significantly upregulated in AML patients at the time of diagnosis (Zhang et al., 2009). This finding raises the possibility that miR-100 might have an important role in the development or pathogenesis of AML. However, the molecular basis for this phenotype has not been elucidated, and the status of the downstream targets of miR-100 in AML remains unknown.

In the present study, we explored the functional role of miR-100 in AML. We found that miR-100 was highly expressed in AML, particularly in acute granulocytic leukemia, and the expression levels of miR-100 were related to the stage of the maturation block underlying the myeloid leukemia subtypes. In vitro experiments further demonstrated that miR-100 overexpression in AML cells inhibited RBSP3 and in turn led to an increase in the level of phosphorylated $\mathrm{pRB}$ and in the release of E2F1. These events promoted cell proliferation and blocked granulocyte/monocyte differentiation. The present results suggest that miR-100 may serve as a novel therapeutic target in AML.

\section{Results}

MiR-100 expression is upregulated in primary $A M L$ Using diagnostic BM samples, we analyzed miR-100 expression in 48 patients with AML, 9 with the AMLM1 (according to the FAB classification) subtype, 7 with AML-M2, 18 with AML-M3, 4 with AML-M4 and 10 with AML-M5. Five BM samples from healthy donors were analyzed as controls. The characteristics of the patients were shown in Table 1. Figure 1a showed that miR-100 is expressed at low levels in total nucleated cells from BM of healthy donors. Upregulated miR-100 expression was detected in almost all of the subtypes, and the expression of miR-100 was much higher in AML- M1, M2 and M3 (Figure 1a). More interestingly, miR-100 was detected at the higher levels of expression in the AML-M1 presenting the immature myeloid phenotype, and slightly increased its expression in the myeloblastic AML-M2 subtype and at the highest
Table 1 AML patients' characteristics

\begin{tabular}{|c|c|c|}
\hline Characteristics & Median (range) & No. $(\%)$ \\
\hline \multicolumn{3}{|l|}{ Sex } \\
\hline Male & & $25(52.0)$ \\
\hline Female & & $23(47.9)$ \\
\hline WBC count, $\times 10^{9} / l$ & $46.3 .5(1.2-671.22)$ & \\
\hline Less than 10 & & $20(41.6)$ \\
\hline $10-50$ & & $12(25.0)$ \\
\hline 50 or higher & & $7(14.5)$ \\
\hline Not in detail & & $9(18.7)$ \\
\hline \multicolumn{3}{|l|}{$F A B$} \\
\hline M1 & & $9(15.5)$ \\
\hline M2 & & $7(12.1)$ \\
\hline M3 & & $18(31.0)$ \\
\hline M4 & & $4(6.8)$ \\
\hline M5 & & $10(17.2)$ \\
\hline \multicolumn{3}{|l|}{ Cytogenetics } \\
\hline ABL1/ETO & & $22(45.8)$ \\
\hline PML/RARA & & $16(33.3)$ \\
\hline Both negative & & $10(20.8)$ \\
\hline
\end{tabular}

Abbreviations: AML, acute myelogenous leukemia; CR: complete remission with 3 years clinical follow-up; FAB: French-AmericanBritish classification; PML/RARA: promyelocytic leukemia/retinoic acid receptor alpha; WBC, white blood cell.

levels of expression in primary AML-M3. These results showed that miR-100 exhibited high expression in myeloid cells that commit to differentiate to granulocyte and monocyte cells in normal program while differentiation arrest in AML, strongly implying the relationship of upregulation of miR-100 and myeloid cell's differentiation block.

We have also detected the expression of miR-100 precursor in the clinical samples (Figure 1b) and found that miR-100 precursor is extremely higher in AML-M1, M2 and M3, consistent with mature miR-100 expression. These results suggest that aberration of miR-100 expression was not at the processing level.

Upregulation of miR-100 arrests human granulocyte and monocyte differentiation and promotes cell survival

To investigate the potential role of miR-100 in myeloid cell differentiation, especially in promyeloid stages, we first examined the expression profiles of miR-100 during the differentiation of the myeloid leukemia cell line HL60 during induction with all-trans retinoic acid (ATRA) and 1,25-dihydroxy-vitamin D3 (1,25D $)$, which can inhibit cell growth and induce granulocyte and monocyte phenotypes, respectively (Supplementary Figures S1 and S2) (Collins et al., 1990; Ji and Studzinski, 2004). The expression of miR-100 was detected at $48 \mathrm{~h}$ and $96 \mathrm{~h}$ after the treatments. The miR-100 expression level decreased in response to both drugs in a dose-dependent (Figures 1c and d) and time-dependent manner (Figures 1e and f). Moreover, miR-100 precursor expression was determined after $12 \mathrm{~h}$ and $96 \mathrm{~h}$ of ATRA and $1,25 \mathrm{D}_{3}$ treatment by northern blot (Figure 1g). A reduced expression level of miR-100 

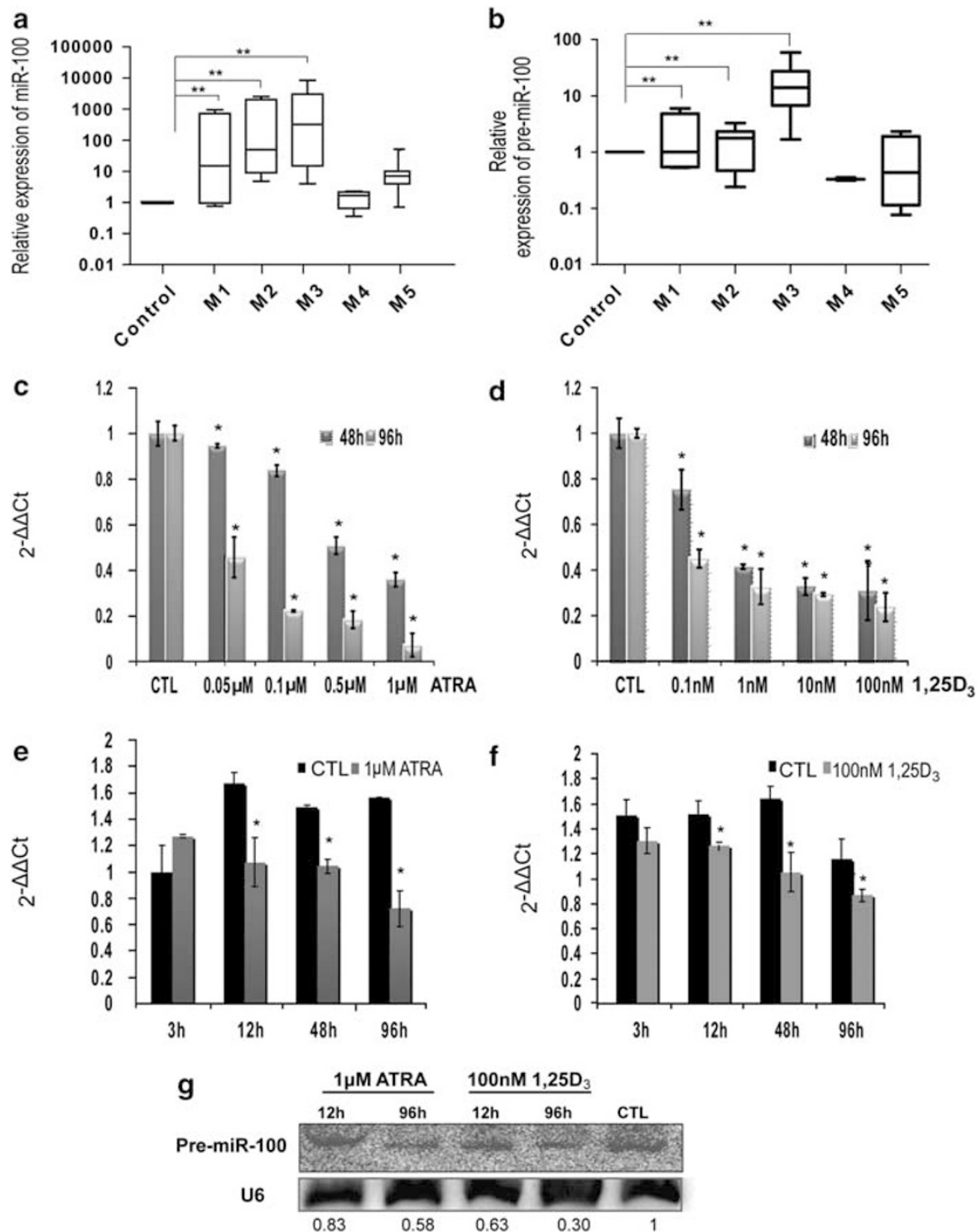

Figure 1 Expression of miR-100 in AML patients and the human leukemia cell line HL60 following induction with all-trans retinoic acid (ATRA) and 1 $\alpha, 2,5$-dihydroxyvitamin D3 $\left(1,25 \mathrm{D}_{3}\right)$. (a, b) The expression level of mature miR-100 (a) and miR-100 precursor (b) in AML patients (from AML M1 to M5), respectively, was quantified by real-time PCR, normalized to the expression of U6 and presented as the $2^{-\Delta \Delta \mathrm{Ct}}$ value relative to the normal samples. Both mature miR-100 and miR-100 precursor was significantly upregulated in the M1, M2 and M3 subtypes in comparison with the healthy controls, but a low expression level was detected in the M4, M5 subtypes $(* * P<0.01)$. (c, d) MiR-100 expression was detected in HL60 cells after $48 \mathrm{~h}$ and $96 \mathrm{~h}$ of treatment with different concentrations of ATRA (c) and 1,25D3 (d) by qRT-PCR, respectively. (e, f) A time-dependent downregulation of miR-100 in HL60 cells was observed following exposure to $1 \mu \mathrm{M}$ ATRA (e) and $100 \mathrm{~nm} 1,25 \mathrm{D}_{3}$ (f). The asterisks demonstrate statistically significant differences compared with the corresponding vehicle-treated control $(\mathrm{CTL})\left({ }^{*} P<0.05\right)$. (g) MiR-100 precursor expression was determined at $12 \mathrm{~h}$ and $96 \mathrm{~h}$ after treatment of $1 \mu \mathrm{m}$ ATRA or $100 \mathrm{~nm} 1,25 \mathrm{D} 3$, respectively, by Northern blot. The value under each sample indicates the fold change of miR-100 precursor level in ATRA- or 1,25 $\mathrm{D}_{3}$-treated cells, relative to that in CTL. A full colour version of this figure is available at the Oncogene journal online.

precursor is similar to that of same as mature miR-100 during both granulocytic and monocytic differentiation, which suggested that miR-100 negatively regulated promyeloid cell terminal differentiation.

Next, we examined whether the overexpression of miR-100 could arrest cell differentiation. HL60 cells were transfected with the negative control RNA duplex (denoted miR-NC) or miR-100 mimics, and then treated with either ATRA or $1,25 \mathrm{D}_{3}$. The miR-NC has been demonstrated to have minimal sequence identity with human miRNA (Dharmacon, Lafayette, CO, USA). Transfection efficiency of miR-100 mimics was determined by qRT-PCR (Supplementary Figure S3A).

As shown in Figures 2a and $\mathrm{b}$, the expression levels of both CD11b and CD15 increased following ATRA treatment. Notably, miR-100-transfected cells clearly displayed low expression levels of the differentiation markers in comparison with miR-NC-transfected cells 
a
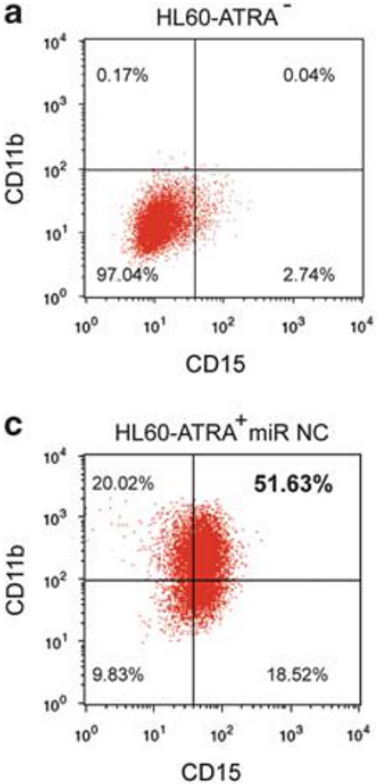

e
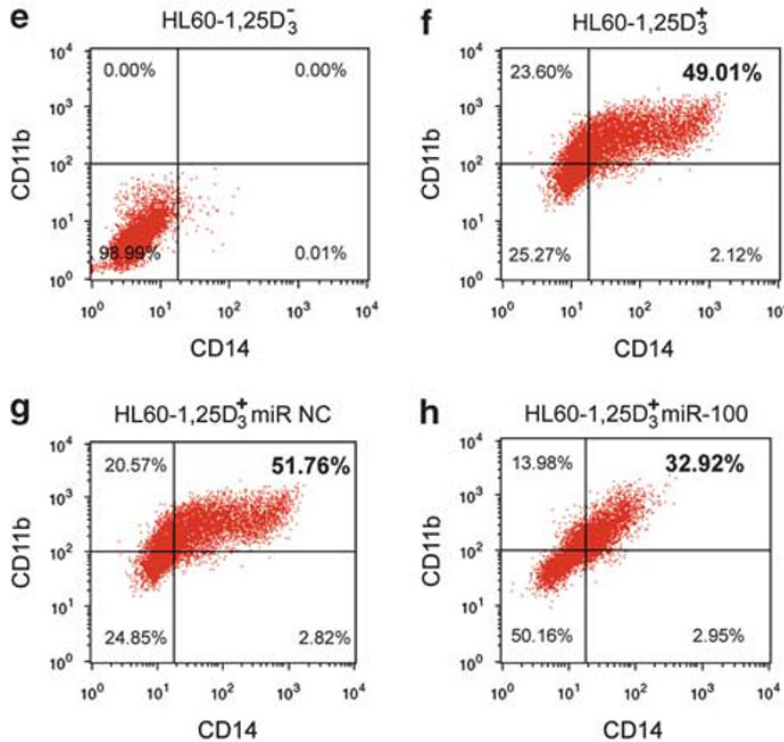
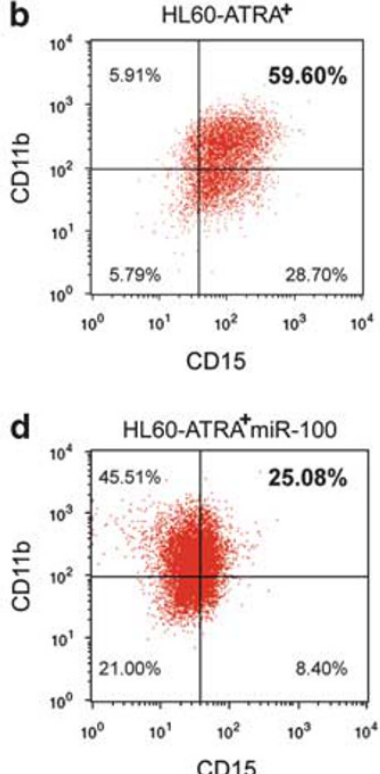

f

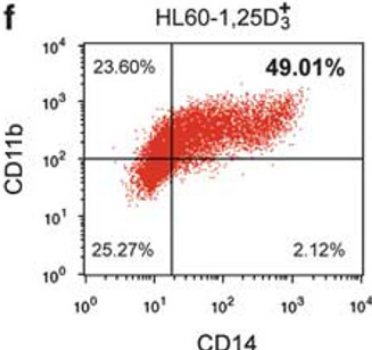

HL60-1,25D ${ }_{3}^{+}$

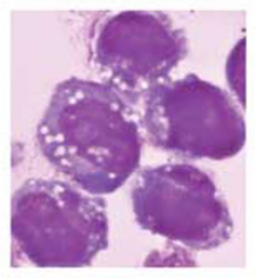

k
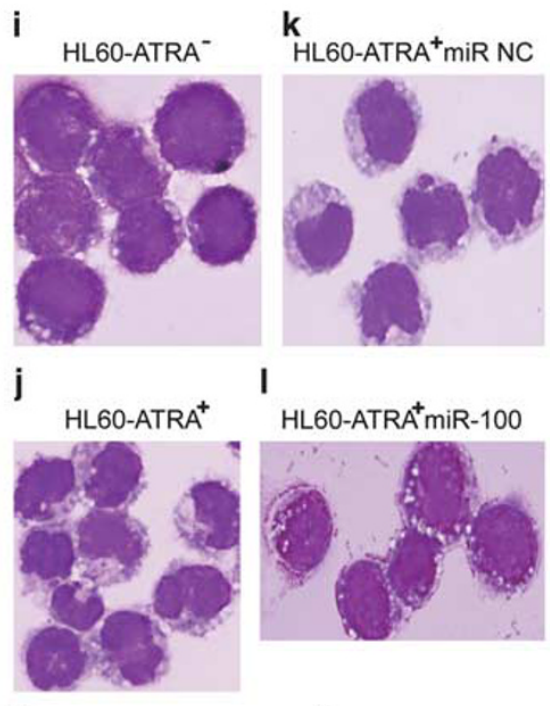

n

HL60-1,25D ${ }_{3}^{-}$

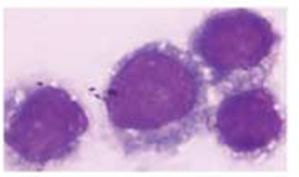

p

HL60-ATRA ${ }^{+}$miR-100
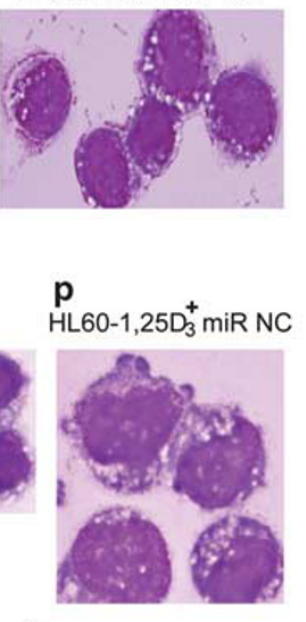

q HL60-1,25D ${ }_{3}^{+}$miR-100

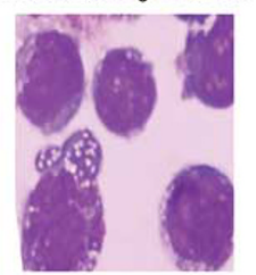

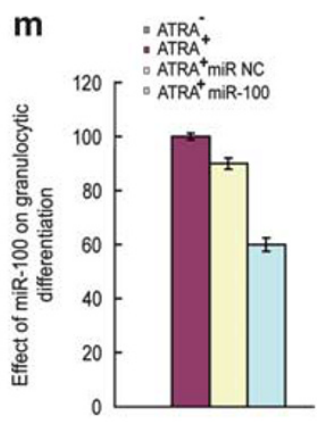

$\mathbf{r}=1,250^{\circ}$

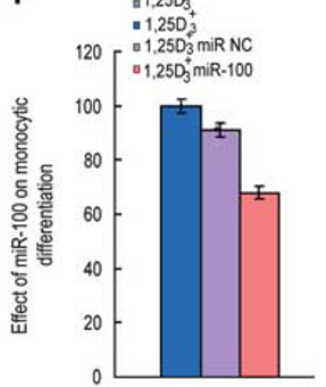

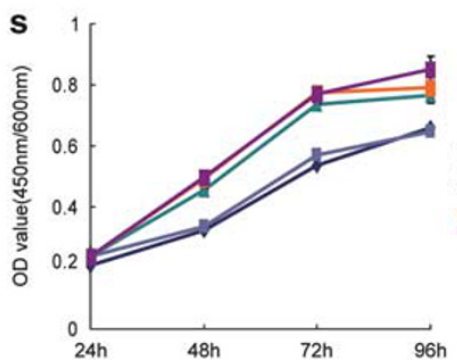

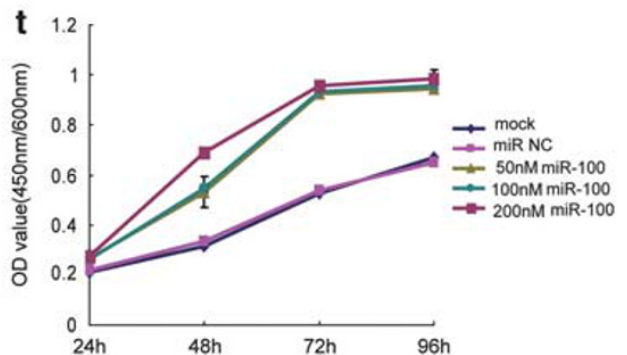

Figure 2 Role of miR-100 in granulocytic/monocytic differentiation and myeloid cell proliferation. (a-d) Transient transfection of HL60 cells with miR-100 blocked the granulocytic differentiation induced by ATRA. Percentage of CD11b and CD15 positive cells in HL60 cells $72 \mathrm{~h}$ after electroporation with $\mathrm{H}_{2} \mathrm{O}$ or the miRNA duplex as follows: $\left(\right.$ a) $\mathrm{H}_{2} \mathrm{O}$ without ATRA, (b) $\mathrm{H}_{2} \mathrm{O}$ with ATRA, (c, d) miR NC or miR-100 mimics with ATRA. (e-h) Experiments corresponding to a-d but with 1,25D3 treatment and percentage of CD11b and CD14-positive cells were determined. (i-m) Morphological analysis of HL60 cells at day 4 after electroporation with $\mathrm{H}_{2} \mathrm{O}$ or the miRNA duplex as follows: (i) $\mathrm{H}_{2} \mathrm{O}$ without ATRA, (j) $\mathrm{H}_{2} \mathrm{O}$ with ATRA, (k) miR-NC with ATRA and (l) miR-100 duplex with ATRA. A representative experiment is shown. (m) Graphic representation of the morphological data corresponding to the mean of three independent experiments. The number of differentiated granulocytic cells compared with the number of undifferentiated cells (without ATRA). (n-r) Experiments corresponding to $\mathbf{i}-\mathbf{m}$ but with 1,25D3 treatment. (s, t) MiR-100 significantly promotes cell proliferation in HL60 (s) and NB4 (t) cells used CCK-8 assay kit. All of the values in the histograms represent the means \pm s.e.m. of triplicate determinations. 
(Figures $2 \mathrm{a}-\mathrm{d}$ ). In particular, the expression of CD15 was reduced significantly. A maturation arrest of monocytic differentiation was also observed. As shown in Figures $2 \mathrm{~g}$ and $\mathrm{h}$, the markers of monocytic differentiation CD11b and CD14 were reduced in miR-100transfected HL60 cells in response to treatment with $1,25 \mathrm{D}_{3}$ (Figures 2e-h). The differentiation toward granulocytic/monocytic lineages was further confirmed based on morphology (Figures 2i-r). These results indicated that miR-100 overexpression could significantly prevent differentiation toward both lineages.

In addition, we assessed whether miR-100 had an effect on cell proliferation using the CCK-8 assay. As expected, the proliferation of HL60 cells was stimulated by the overexpression of miR-100 (Figure $2 \mathrm{~s}, P<0.05$ at $48 \mathrm{~h}$ and $P<0.01$ from $72 \mathrm{~h}$ to $96 \mathrm{~h}$ ), and this effect was time-dependent. However, no clear dose-dependent effect was detected. Similar results were observed in NB4 cells (Figure 2t, $P<0.01$ ). These data suggested that miR-100 might function as an oncogene and contribute to AML progression by blocking myeloid cell differentiation and promoting proliferation.

\section{MiR-100 targets the phosphatase-like gene RBSP3 via translational repression}

The elucidation of miRNA targets remains a major issue in functional investigations of miRNAs. Putative targets of miR-100 were searched using TargetScan (http:// www.targetscan.org/), PICTAR (http://pictar.bio.nyu. $\mathrm{edu} /$ ) and miRBase (http://microrna.sanger.ac.uk/ sequences/index.shtml) and 37 potential targets were predicted. Among the predicted targets, 10 are related to tumorigenesis and thus were selected for further experimental validation (Supplementary Table S1 and part data shown in Supplementary Figure S3). Three putative targets were experimentally confirmed, including RB1 serine phosphates from human chromosome 3 (RBSP3), tribbles homolog 2 (TRIB2) and homeobox A1 (HOXA1). Remarkably, RBSP3 demonstrated the greatest reduction of activity $(40 \%)$. The predicted miR-100-binding $3^{\prime}$ UTR of RBSP3 is conserved in humans, mice and rats (Figure $3 \mathrm{a}$ ), and the interaction between miR-100 and target mRNA sequences was further validated using luciferase reporter assays with a deleted, point and full mutation of putative miR-100 binding sites in the $3^{\prime}$ UTR of the RBSP3 gene (Figures $3 b$ and $c$ ).

To confirm that the RBSP3 protein is suppressed by miR-100, we performed both miR-100 overexpression and knockdown experiments in HL60 cells and examined the expression of RBSP3. As shown in Figure 3d, the level of RBSP3 protein was significantly reduced in HL60 cells that were transfected with the miR-100 mimic, but it was increased in cells that were transfected with the miR-100 inhibitor (antisense), which transfection efficiency was determined by qRT-PCR (Supplementary Figure S3B). These data indicated that RBSP3 is a bona fide target of miR-100 in myelopoiesis.

To further validate the correlation of miR-100 and RBSP3 in vivo, we have choosed 17 cases at random to determine the expression of miR-100 and the protein levels of RBSP3 in primary patients. Figure 3e showed that the expression of RBSP3 is extremely low in AML-M3, and reversely correlated with miR-100 in AML about $76.5 \%$.

The RBSP3 gene is involved in myeloid cell differentiation and cell proliferation via the dephosphorylation of $R B$ and the release of $E 2 F 1$

RBSP3, which has been previously denoted as $H Y A 22$ and $C T D S P L$, is a recently identified phosphatase-like tumor suppressor gene that dephosphorylates the Rb1 serine on Ser-807 and Ser-811 (Kashuba et al., 2004). A recent study revealed that $\mathrm{RBSP} 3$ is involved in the regulation of cell growth and differentiation, and frequent mutations in this gene are detected in human hematopoietic cell lines (Kashuba et al., 2009). However, the function of RBSP3 in leukemia has not yet been elucidated.

To explore whether RBSP3 is involved in myeloid cell differentiation, we first determined the expression level of RBSP3 protein in HL60 cells following induction with ATRA or $1,25 \mathrm{D}_{3}$. A significant increase in RBSP3 protein levels was detected in response to both treatments (Figures 3f and g). Notably, the expression level of RBSP3 increased in a dose- and time-dependent manner (Figure 3h), and this phenomenon correlated negatively with miR-100 expression (Figures 1c-f). The results further demonstrated that RBSP3 reversed the effects of miR-100 and had a role in promyeloid cell differentiation.

To further unravel the function of RBSP3, loss- and gain-function were performed with RNA interference and lentivirus construct, respectively, to confirm the role of this gene in cell differentiation and proliferation. Among two siRNAs duplexes (siRBSP3-1 or 2), siRBSP3-2 caused an obvious reduction in both endogenous mRNA and protein levels in HL60 cells, which was selected for further study (Figure 4a). Meanwhile, RBSP3 protein level was increased in HL60 cells infected by lentivirus-RBSP3 (lv-RBSP3) compared with lentivirus negative control (lv-NC) (Figure 4b). As expected, reduced CD11b and CD15 expression levels were detected in siRBSP3-2-transfected HL60 cells, while increased CD11b and CD15 expression in lentivirus infected ones in comparison with the controls following treatment with ATRA (Figures 4c-h). Similarly, CD11b/CD14 inhibition and elevation was observed in siRBSP3 and lentivirus transducted cells, respectively, following $1,25 \mathrm{D}_{3}$ treatment (Figures $4 \mathrm{i}-\mathrm{n})$. These results suggest that RBSP3 promotes promyeloid cell differentiation. We further explored the role of RBSP3 in cell proliferation using the CCK-8 assay. HL60 cells survival gradually increased from $24 \mathrm{~h}$ to $96 \mathrm{~h}$ following transfection with siRBSP3 (Figure 4o), while suppressed in cells with lentivirus infected (Figure 4p). These results were similar to that obtained in the miR-100 studies, which indicates that RBSP3 functions as a suppressor of cell growth in AML.

Previous studies have shown that RBSP3 can influence the phosphorylation status of $\mathrm{pRB}$ and then 
a

$\begin{aligned} \text { H.sapiens } & \text { AAGGUAAA UACGGGUA UUGUUUUUAAUUAUUAC } \\ \text { M.musculus } & \text { AAGGUAAA UACGGGUA UUGCUUUUAAUUGUAAG } \\ \text { R.norvegicus } & \text { AAGGUAAA UACGGGUA UUGCUUUUAAUUGUCAG }\end{aligned}$

b
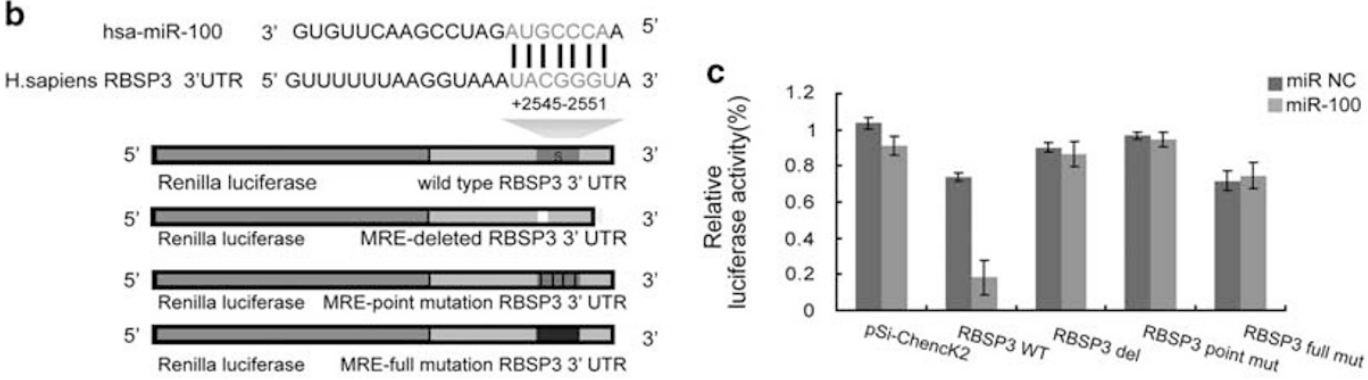

d
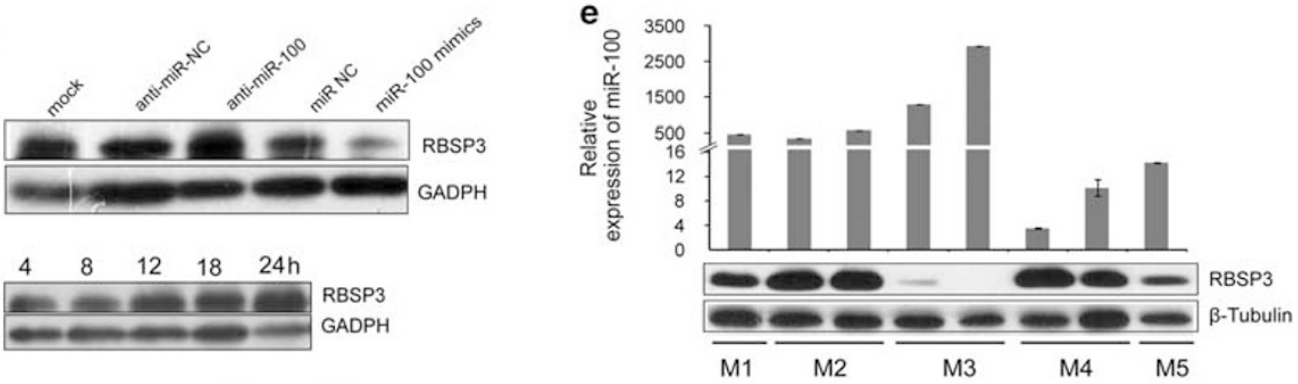

$\begin{array}{llllllll}\text { g } & 4 & 8 & 12 & 18 & 24 & 36 & 48 \mathrm{~h}\end{array}$

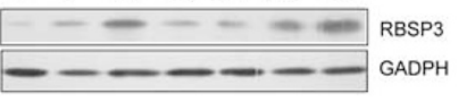

h
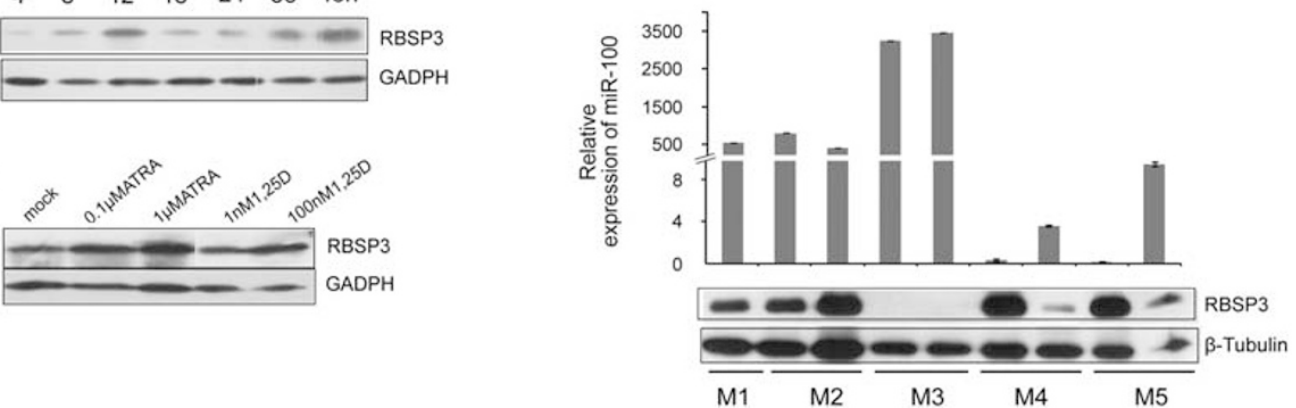

Figure 3 MiR-100 directly targets RBSP3, which responds to ATRA and 1,25D induction. (a) Sequences of the predicted miR-100 binding sites in human, mouse and rat genomic regions. Highly conserved nucleotides are shown in blue. (b) Schematic of the luciferase reporter assay used to validate the interaction between miR-100 and the $3^{\prime}$ UTR of RBSP3. Red font indicates the 'seed' regions. MRE $R B S P 33^{\prime}$ UTR of wild, deleted, point mutant and full mutant were separately inserted into a psiCheck2 vector downstream from the Renilla luciferase gene. (c) Repression of luciferase activity due to the interaction between miR-100 and the luciferase constructs. Each Renilla luciferase reading was normalized to that obtained for the control firefly luciferase. (d) Western blot analysis of the expression level of RBSP3 following the overexpression of miR-100 mimics or the knockdown of endogenous miR-100 using miR-100 antisense in HL60 cells. (e) Inverse correlation of expression levels of miR-100 and RBSP3 protein in AML patients (from AML-M1 to M5) demonstrated by qRT-PCR and western blot. (f, g) Time-course analysis of the induced upregulation of RBSP3 protein in HL60 cells by $1 \mu \mathrm{m}$ ATRA and $100 \mathrm{~nm} 1,25 \mathrm{D}_{3}$, respectively. RBSP3 protein was gradually upregulated from $4 \mathrm{~h}$ to $24 \mathrm{~h}$ after treatment with $100 \mathrm{~nm}$ $1,25 \mathrm{D}_{3}$. (h) Dose-dependent effect of ATRA and $1,25 \mathrm{D}_{3}$ on RBSP3 protein expression at $96 \mathrm{~h}$ after treatments. RBSP3 protein expression increased in a dose-dependent manner following treatment with $0.1 \mathrm{um} / 1$ uм ATRA or $1 \mathrm{~nm} / 100 \mathrm{~nm} 1,25 \mathrm{D}_{3}$. A full colour version of this figure is available at the Oncogene journal online.

the release of E2F1. Next, we asked whether RBSP3 has functional relevance with the reduction of the phosphorylated form of $\mathrm{pRB}$ protein and blockage of E2F1 in myeloid cells. To address this issue, we transfected siRBSP3 into HL60 cells and found that the expression levels of $\mathrm{pRB}$ and $\mathrm{E} 2 \mathrm{~F} 1$ protein increased with the downregulation of RBSP3, while the amount of total $\mathrm{RB}$ protein remained approximately the same in all of the treatments (Figure 5a). These data implied that
RBSP3 might have a crucial role in myeloid cell differentiation toward granulocytic/monocytic lineages through the $\mathrm{pRB}-\mathrm{E} 2 \mathrm{~F} 1$ pathway.

MiR-100 regulates cell differentiation and survival via its target RBSP3, which in turn modulates the cell cycle effector $p R B / E 2 F 1$ in myeloid cells

As we demonstrated that miR-100 could block differentiation and promote proliferation in AML cells by 
repressing the expression of $\mathrm{RBSP} 3$, a bona fide target of miR-100, and RBSP3 has a crucial role in cellular differentiation and proliferation in the myeloid lineage through pRB-E2F1, we hypothesized that miR-100 might contribute to the pathogenesis of AML via the RBSP3-pRB-E2F1 pathway.

We tested these hypotheses by transfecting miR-100 mimics and the miR-100 inhibitor into HL60 cells. The

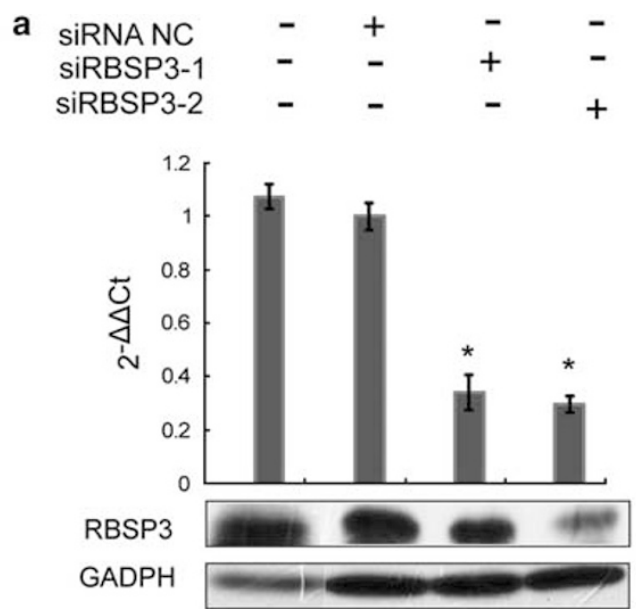

b IV-NC IV-RBSP3

RADPH



C

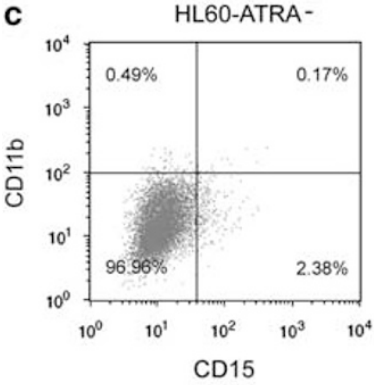

e

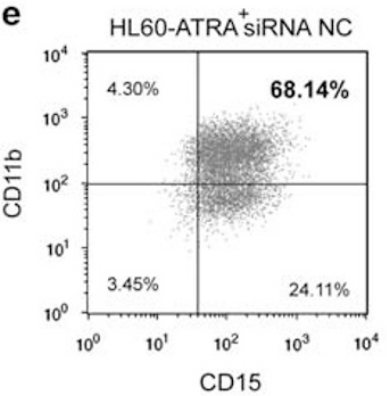

g

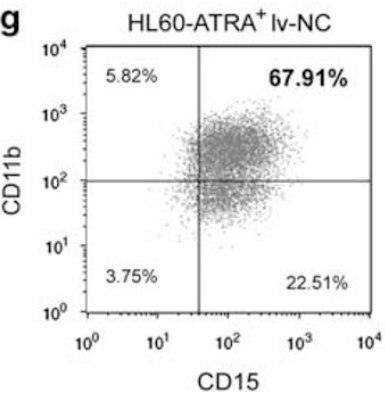

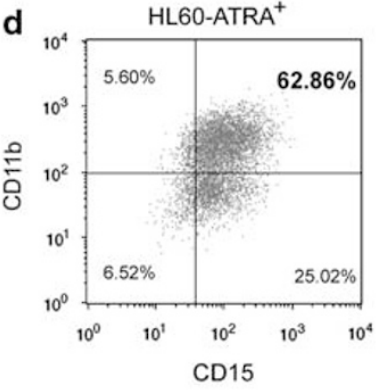
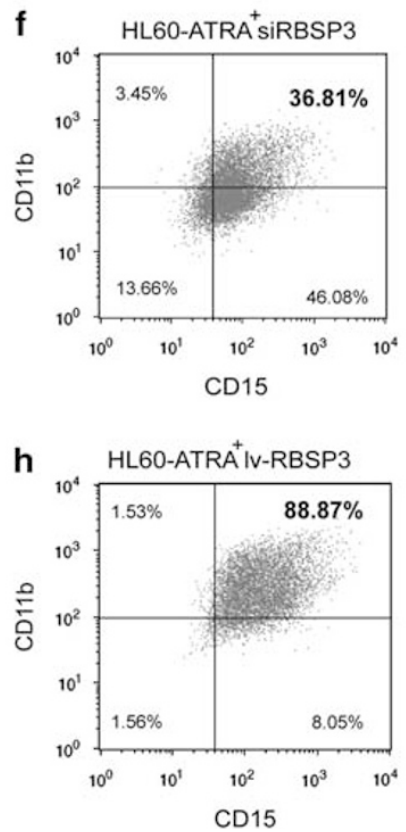
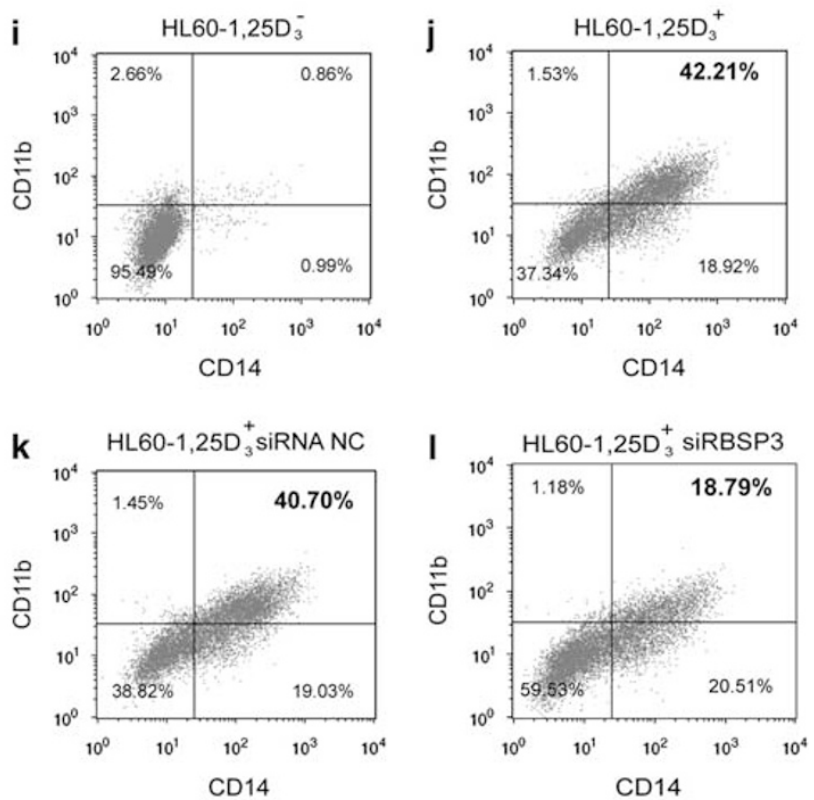

m
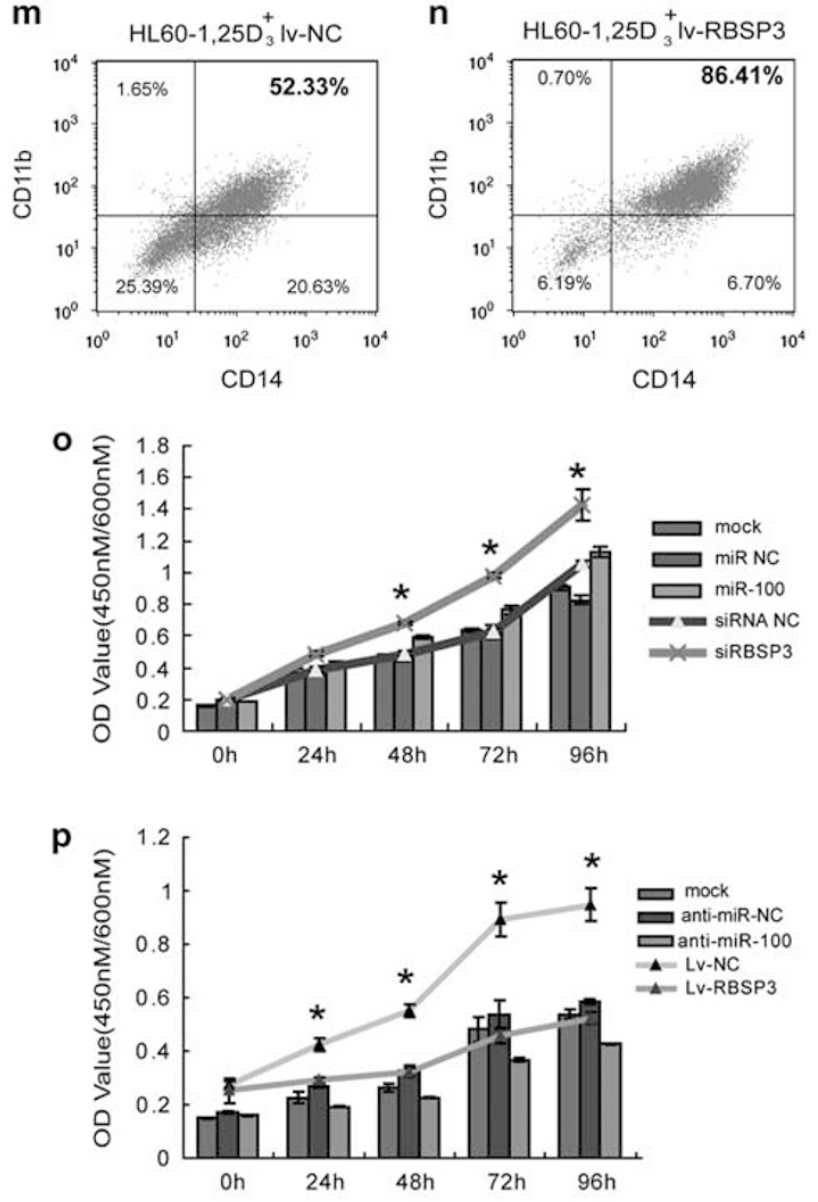

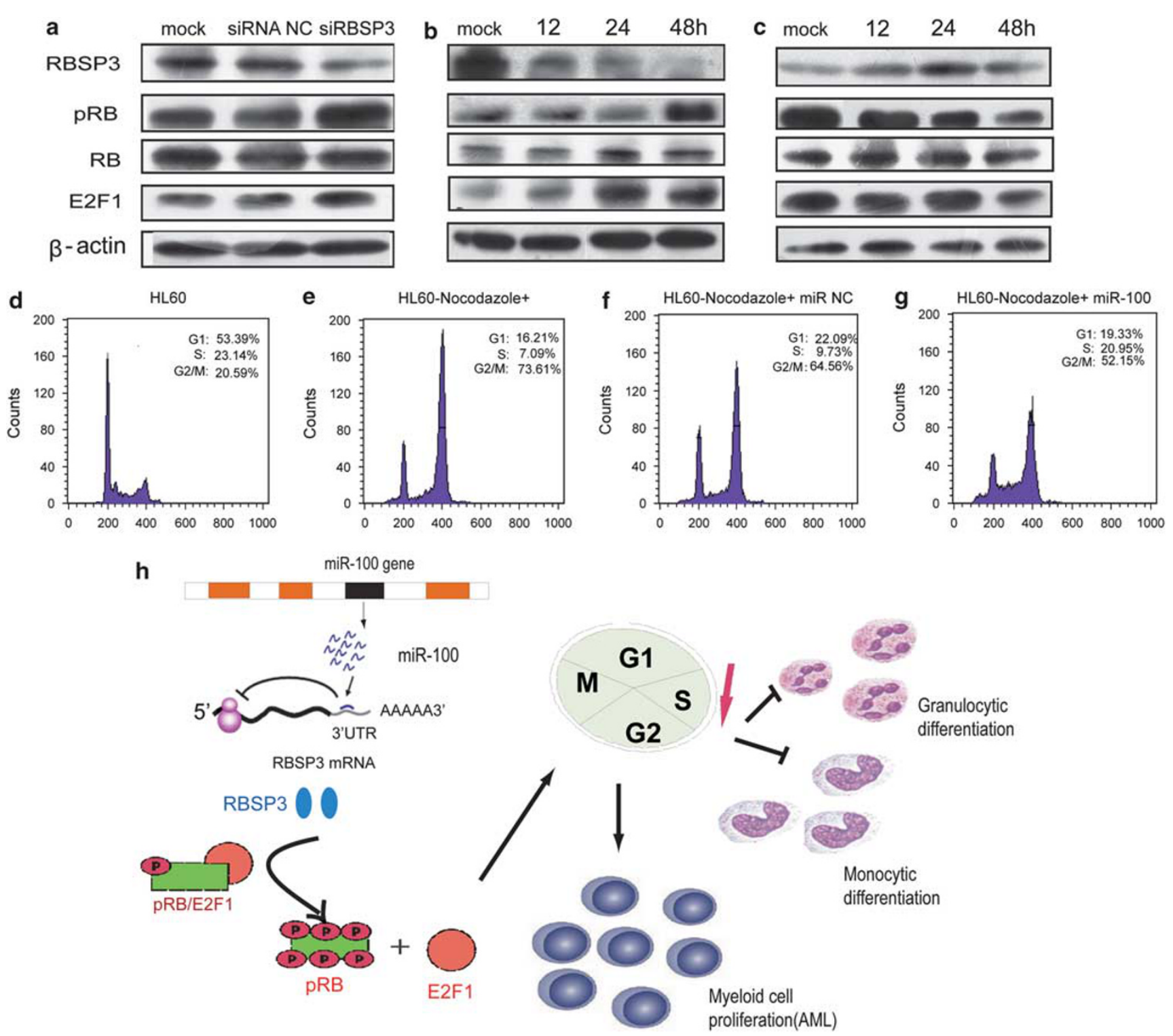

Figure 5 MiR-100 targets RBSP3, which modulates the cell cycle effectors pRB/E2F1 and is involved in myeloid cell differentiation and proliferation. (a) RBSP3 knockdown promoted the phosphorylation of Rb and E2F1. After $72 \mathrm{~h}$ transfection with siRNA NC or siRBSP3, cells were collected to analyze the expression of RBSP3, pRb (phosphorylated $\mathrm{Rb}$ ), Rb (total Rb protein) and E2F1 by western blotting using $\beta$-actin as an internal control. (b) MiR-100 overexpression induced the expression of pRB and E2F1 by downregulating RBSP3. The cells were collected at the indicated time points for western blot analysis. (c) The knockdown of miR-100 expression results in an upregulation of RBSP3 expression and a downregulation of pRB and E2F1 expression. Cells were collected at the indicated time points after transfection with miRNA antisense. Protein expression was assessed by western blot analysis. pRb, phosphorylated $\mathrm{Rb}$; $\mathrm{Rb}$, total $\mathrm{Rb}$ protein; $\beta$-actin, internal control. (d-g) MiR-100 promoted entry into S-phase of the cell cycle. (d) The cell cycle phase was analyzed by FACS at $24 \mathrm{~h}$ after the transfection with $\mathrm{H}_{2} \mathrm{O}$ in HL60 cells (without nocodazole). (e-g) Cell cycle phase data in HL60 cells transfected with $\mathrm{H}_{2} \mathrm{O}$, miR-NC or miR-100 (with nocodazole). The data correspond to the mean of three independent experiments $(P<0.05)$. (h) Schematic representation of a pathway modulated by miR-100 in myeloid cells undergoing differentiation toward granulocytosis/monocytosis and proliferation in AML. MiR-100 overexpression in myeloid cells induced progression through the G1/S transition and promoted S-phase entry. Thus, miR-100 induced cell proliferation and blocked promyeloid differentiation by repressing its downstream target RBSP3, which in turn resulted in the phosphorylation of RB and an accumulation of the downstream cell cycle effector E2F1.

Figure 4 RBSP3 is involved in myeloid cell differentiation and cell proliferation. (a) The qRT-PCR and western blot analysis of the effects of different items of siRBSP3. ${ }^{*} P<0.05$. (b) Western blot analysis of the infection efficiency of Lentivirus RBSP3. (c-h) CD11b/ CD15 expression following transfection with $\mathrm{H}_{2} \mathrm{O}$, siRBSP3 or lv-RBSP3 by FACS $(P<0.05)$ : $(\mathbf{c}, \mathbf{d}) \mathrm{H}_{2} \mathrm{O}$ without or with ATRA, $(\mathbf{e}, \mathbf{f}) \mathrm{miR}$ NC or miR-100 with ATRA and $(\mathbf{g}, \mathbf{h})$ lv-NC and lv-RBSP3 with ATRA.A representative experiment is shown. (i-n) Corresponding FACS experiments with $\mathbf{c}-\mathbf{h}$ but the cells were treated with 1,25D3. A representative experiment is shown. (o) The transfection of HL60 cells with siRBSP3 significantly promoted myeloid cell proliferation. Cell viability was determined using the CCK-8 assay. The time points after transfection with H2O, siRNA NC, siRBSP3, miR-NC or miR-100 are indicated. (p) Corresponding FACS experiments with (o) but the cells were transfected with $\mathrm{H}_{2} \mathrm{O}$, anti-miR-NC, anti-miR-100, lv-NC or lv-RBSP3. ${ }^{*} P<0.05$. A full colour version of this figure is available at the Oncogene journal online. 
overexpression of miR-100 resulted in the downregulation of RBSP3 protein at different time points. However, the expression levels of the $\mathrm{pRB}$ and $\mathrm{E} 2 \mathrm{~F} 1$ proteins increased, and the total levels of $\mathrm{RB}$ protein remained the same at all time points (Figure 5b). Meanwhile, the results for the protein expression levels of RBSP3, pRB and E2F1 in anti-miR-100 transfectants were opposite with those obtained for miR-100, excluding the findings determined for RB, which remained unchanged in any case (Figure 5c). These results support the hypothesis that miR-100 regulates the RBSP3-pRB-E2F1 pathway at the level of translation.

Because the downstream target E2F1 is a master cell cycle regulator, we also analyzed the cell cycle by FACS to identify $\mathrm{S}$ activation via the overexpression of miR100. The transfected cells were synchronized by treatment with nocodazole, which depolymerizes the microtubules and blocks the cell cycle at G2/M-phase. After $24 \mathrm{~h}$ of synchronization, cells were determined by FACS analysis. Results showed that a substantial increase in the G2 population was observed, while most of the miR-100-transfectants could escape this block and enter S-phase (Figures $5 \mathrm{~d}-\mathrm{g}$ ). These results further support the hypothesis that miR-100 activates the downstream effector E2F1 and promotes S-phase entry.

Collectively, these results demonstrate that miR-100 contributes to AML pathogenesis by targeting the RBSP3-pRB-E2F1 pathway to affect cell proliferation and differentiation.

\section{Discussion}

The inhibition of hematopoietic precursor differentiation is a characteristic of different types of AML. Several studies have shown that genome-wide gene expression patterns are highly related to different subtypes of AML, and have provided a better understanding of the underlying biology of this disease. Recently, miRNAs have emerged as important cellular regulators that mediate cellular development and differentiation. Previous studies have shown that miR100 is aberrantly expressed in several types of leukemia, including AML with $\mathrm{t}(15 ; 17)$ or inv(16) (Dixon-McIver et al., 2008; Li et al., 2008). In the present study, we found that miR-100 inhibits differentiation of myeloid cells toward granulocyte/monocyte lineages. The underlying molecular pathway responsible for the effects of miR-100 in myeloid leukemia cell survival and differentiation might control the $\mathrm{G} 1$ to $\mathrm{S}$ phase transition by repressing RBSP3, which modulates the RB-E2F1 signaling pathway. We propose that a high expression level of miR-100 may disrupt the cell cycle control, promote cell proliferation, block cell differentiation and consequently facilitate the development of cancers such as AML. These effects characterize a new role for miR-100.

Two observations confirm our hypothesis. First, we observed a differential expression pattern of miR-100 in different subtypes of AML, and interestingly, we found that miR-100 precursor and mature were highly expressed in AML-M1, M2 and M3. In contrast, lower expression levels were noted in other AML subtypes, such as the M4 and M5 phenotypes, in which the cellular programs for monocytic phenotype are already partially established. Actually, our results indicated that miR-100 could block myeloid cell differentiation and promote cell proliferation during both granulocytic and monocytic differentiation. Next, we investigated the molecular pathway that might be controlled by miR100. Several putative targets were predicted and notably, RBSP3 was validated. Importantly, expression of RBSP3 protein is most inverse correlation with miR100 in AML clinical samples. $R B S P 3$ is an important candidate tumor suppressor gene located at $3 \mathrm{p} 21.3$ (Kashuba et al., 2004; Anedchenko et al., 2008; Sinha et al., 2008; Ghosh et al., 2010; Senchenko et al., 2010); however, the involvement of RBSP3 in the regulation of cell differentiation and growth in myeloid cells has not yet been studied. We demonstrated that RBSP3 protein expression was elevated during ATRA- and $1,25 \mathrm{D}_{3}$ induced promyeloid cell differentiation toward granulocytic and monocytic lineages, respectively. Moreover, loss- and gain-function were introduced to demonstrate that RBSP3 is associated with cell differentiation and proliferation with RNA interference and lentivirus constructs. Expression profiles of CD11b/CD15 or CD11b/CD14 have been detected either downregulated or upregulated in knockdown or overexpressed-RBSP3 cells, respectively, which were similar to the results obtained in ectopic miR-100 expression. These results indicate that the activation of the phosphatase RBSP3 protein may be a common step that is required for granulocytic/monocytic differentiation.

Previous studies have also reported that RBSP3 removes the phosphate group from serine 807 and 811 in its substrate, phosphorylated RB (pRB), and thereby, it induces the formation of the RB-E2F1 complex (Ghosh et al., 2010). The 'RB' pathway has a critical role in both cell physiology and tumorigenic transformation via distinct molecular mechanisms, in particular, through the mediation of $\mathrm{G} 1$ progression and the $\mathrm{G} 1 / \mathrm{S}$ transition (Chen et al., 1989; Strauss et al., 1995; Weinberg, 1995; Bartek et al., 1996, 1997; Hall and Peters, 1996; Sherr, 1996). In the present study, overexpression experiments showed that enforced expression of miR-100 could inhibit RBSP3, upregulate pRB and release $\mathrm{E} 2 \mathrm{~F} 1$. The release of $\mathrm{E} 2 \mathrm{~F} 1$ blocks the differentiation induced by ATRA or $1,25 \mathrm{D}_{3}$ and promotes the survival of HL60 cells. The knockdown experiment revealed that the loss of miR-100 provided the opposite result. These findings indicate that the aberrant expression of pRB-E2F1 and RBSP3 during differentiation and proliferation might be correlated with the expression level of miR-100. In AML cells, a high expression level of miR-100 represses the expression of RBSP3, which in turn leads to increased pRB phosphorylation and $\mathrm{E} 2 \mathrm{~F} 1$ release. The release of E2F1 might provide a G1/S transition checkpoint and activate progression through S-phase, thus arresting promyeloid cell differentiation, inducing proliferation and leading to AML progression. The schematic representation of the role of 
miR-100/RBSP3/pRB/E2F1 in granulocyte/monocyte differentiation and proliferation in $A M L$ is shown in Figure 5h.

To date, an increasing number of studies have revealed that miRNAs have an important role in AML. For example, Garzon et al. (2009) found that miR-29b has a tumor suppressor function and affects the survival of AML cells by targeting MCL-1 and upregulating BIM and PDCD4 transcripts. Liu et al. (2010) discovered the $\mathrm{Sp} 1 / \mathrm{NFkB} / \mathrm{HDAC} / \mathrm{miR}-29 \mathrm{~b}$ regulatory network in KITdriven AML. Pigazzi et al. (2009) demonstrated that miR-34b targets the cyclic AMP-responsive elementbinding network in AML. Recently, Pulikkan et al. (2010) reported that E2F1 and miR-223 comprise an autoregulatory negative feedback loop in AML. E2F1 is a cell cycle regulator, inhibits granulopoiesis and induces myeloid cell cycle progression (Strom et al., 1998). E2F1 is regulated directly by miR-330 in prostate cancer cells (Lee et al., 2009), by miR-149* in neuroblastoma cells and HeLa cells (Lin et al., 2010) and by miRNA-331-3p in gastric cancer cells (Guo et al., 2010). In addition, $1,25 \mathrm{D}_{3}$ induces monocytic phenotype differentiation in HL-60 human myeloid leukemia cells, and this process is mediated by Akt through Raf/MEK/ERK MAPK signaling (Wang et al., 2009). To our knowledge, this is the first report to clearly demonstrate the mechanism by which miR-100 inhibits RBSP3 during granulopoiesis and monocytic differentiation. MiR-100 targets RBSP3 and regulates its expression in AML, which reveals a new post-transcriptional mechanism of regulation in the myeloid lineage. In addition, another kinase mTOR was also validated as a target of miR-100 in AML in this study, suggesting that miR-100 may involve in a complicated network. The manipulation of miR-100 could be diagnostically and therapeutically relevant to treat AML subtypes.

\section{Materials and methods}

Patients, sample collection and therapeutic methods A total of 48 AML patients and five healthy donors from the First and Second Affiliated Hospital of Sun Yat-sen University were enrolled in the study. The demographics for all of the patients are presented (see Table 1). The BM from patients and healthy donors was collected via a BM puncture at the time of diagnosis or during the follow-up process. Written informed consent to perform the biological studies was obtained from all of the patients, and the study was approved by the Ethics Committee of the affiliated hospitals at Sun Yat-sen University.

\section{RNA analysis}

Total RNA was extracted using Trizol reagent (Invitrogen, Carlsbad, CA, USA) according to the manufacturer's instructions. The following oligonucleotides were used as probes for mature miR-100: RT primer, 5'-GTCGTATCCAGTGCAG GGTCCGAGGTATTCGCACTGGATACGACCACAAG-3'; PCR forward primer, 5'-GCGGC AACCCGTAGATCCGAA-3'; PCR reverse primer, 5'-GTGCAGGGTCCGAGGT-3'. Endogenous U6 small nuclear RNA was detected as an internal control using the following oligonucleotides: forward primer,
5'-CGCTTCGGCAGCACATATAC-3'; reverse primer, 5'-TT CACGAATTTGCGTGTCAT- $3^{\prime}$. MiR-100 precursor primers were designed as describe previously (Jiang et al., 2005). PCR forward primer: 5'-AACCCGTAGATCCGAACTTG-3'; PCR reverse primer: 5'-TACCTATAGATACAAGCTTGTGCG- $3^{\prime}$. U6 small nuclear RNA forwards primer: 5'-CTCGCTTCGG CAGCACA-3'; reversed primer: 5'-AACGCTTCACGAATT TGCGT-3'. The miR-100 precursor and U6 reverse transcription primers were used as the reverse primer. Where indicated, both miRNA mature and precursor quantification was performed by real-time PCR with an ABI PRISM 7900 Sequence Detection System (Applied Biosystems, Foster City, $\mathrm{CA}$, USA). The delta $\mathrm{Ct}$ values were normalized to those obtained from the amplification of endogenous U6 small nuclear RNA. All of the reactions were performed in triplicate. Real-time PCR was performed to quantify the mRNA expression using ExTaq SYBR Green Supermix (Bio-Rad, Hercules, CA, USA) according to the manufacturer's instructions. The following oligonucleotides were used for RBSP3: forward primer, 5'-CGCTTCGGCAGCACATATAC-3', reverse primer $5^{\prime}$-TTCACGAATTTGCGTGTCAT-3'. The $R B S P 3$ transcript was detected using the TaqMan oligonucleotides HS 00325656.m1 (Applied Biosystems). The delta Ct values were normalized to those obtained from the amplification of endogenous $\beta$-actin mRNA using the Quantitect Primer Assay (Qiagen, Guangzhou, China). All of the reactions were performed in triplicate.

\section{Northern blot}

HL60 cells were treated with $1 \mu \mathrm{m}$ ATRA and $100 \mathrm{~nm} 1,25 \mathrm{D}_{3}$ at $12 \mathrm{~h}$ and $96 \mathrm{~h}$, respectively. Total RNA was extracted with Trizol reagent (Invitrogen) according to the manufacturer's instructions. In all, $80 \mu \mathrm{g}$ of total RNA was separated on a $15 \%$ denaturing polyacrylamide gel, transferred to positively charged membrane (PerkinElmer, Boston, MA, USA) using Trans-Blot semi-dry eletrophoretic transfer cell (Bio-Rad) and then immobilized by UV crosslinking at $354 \mathrm{~nm}$ for $4 \mathrm{~min}$ each face and baking at $80{ }^{\circ} \mathrm{C}$ under vaccum for $50 \mathrm{~min}$. The membranes were pre-hybridized and then hybridized at $42{ }^{\circ} \mathrm{C}$ for $24 \mathrm{~h}$ to a $\gamma-{ }^{32} \mathrm{P}$-labeled DNA oligonucleotide that was complementary to the sequence of miR-100 precursor (probe sequence: $5^{\prime}$-CTTGTGCGGACTAATACCACAAGT TCGGATCTACGGGTT-3' and U6: 5'-CCATGCTAATCT TCTCTGTATC- $3^{\prime}$ ) thereafter, the membranes were washed and exposed to a Storage Phosphor Screen, which was subsequently read with STORM 820 Phosphor Imager (Amersham Bioscience, Sunyvale, CA, USA).

\section{Vector constructs}

The $3^{\prime}$-untranslated terminal region (UTR) segment comprising $59 \mathrm{bp}$ of the $3^{\prime}$ UTR of RBSP3 was synthesized by Sangon (Shanghai, China) and inserted into the psiCheckcontrol vector (Promega, Madison, WI, USA) for the miRNA functional analysis. The RBSP3 deleted/psiCheck-RBSP3deleted vector, which spanned $8 \mathrm{bp}$ of the site of perfect complementarily to miR-RBSP3, was generated by PCR deletion. The RBSP3 point mutated/psiCheck-RBSP3-point mutated vector was mutated at $1,3,4,6$ and 8 point, and the RBSP3 full mutated/psiCheck-RBSP3-full mutated vector was full mutation of the perfect complementarily site, respectively. Wild type, deleted insertions, point mutation and full mutation were confirmed by DNA sequencing.

\section{Statistical analysis}

The Fisher's exact test, $t$-test and $\chi^{2}$-test were used to compare baseline characteristics and the average miRNA expression 
levels between groups of patients and between patients and normal donors. Other data are expressed as the mean \pm s.e.m. of at least three independent experiments. The differences between groups were analyzed using the Student's $t$-test when only two groups were compared or one-way analysis of variance when more than two groups were compared. $P<0.05$ was considered statistically significant.

\section{Cell lines and transient transfection}

Two human acute myeloid leukemic cell lines, HL60 and NB4, were cultured in RPMI 1640 medium (Invitrogen). The human embryonic kidney cell line HEK-293T was grown in Dulbecco's modified Eagle's medium (Invitrogen). Both cultures were supplemented with $10 \%$ fetal bovine serum (fetal bovine serum, Australia) and sodium pyruvate and cultured at $37^{\circ} \mathrm{C}$ in a humidified atmosphere consisting of $5 \% \mathrm{CO}_{2}$.

For the luciferase reporter assay, HEK-293T cells were grown in 24-well plates at a density of $1 \times 10^{5}$ cells per well in $0.5 \mathrm{ml}$ of complete growth medium. The cells were transfected using Lipofectamine 2000 (Invitrogen) according to the manufacturer's protocol.

The following were purchased from GenePharma (Shanghai, China): miR-100 mimics; miR-NC, a miRNA negative control; miR-100 antisense with a sequence complementary to mature miR-100; and miR antisense $\mathrm{NC}$, a negative control for miR-100 antisense. The small interfering RNAs (siRNA) against human RBSP3 (GenBank Access. No. NM_005808) transcripts (denoted siRBSP3) and the negative control RNA duplex (denoted SiRNA NC) were purchased from Guangzhou Ribo-Bio Co., Ltd. (Guangzhou, China).

HL60 and NB4 cells were grown in 24-well plates containing a density of $1 \times 10^{6}$ cells per well in $0.5 \mathrm{ml}$ of complete growth medium. The cells were transfected with the small molecular RNAs mentioned above using the Neon Transfection System (Invitrogen). The electroporation conditions were as follows: $1350 \mathrm{~V}, 35 \mathrm{~ms}$ width and one pulse for HL60 cells; $1400 \mathrm{~V}, 10 \mathrm{~ms}$ width and three pulses for NB4 cells.

\section{Luciferase reporter assay}

Transient transfections were performed in HEK-293T cells with $100 \mathrm{~nm}$ miR-100 mimics or miR-100 negative control; $0.1 \mu \mathrm{g}$ of psiCheck control or psiCheck-RBSP3; or psiCheck-RBSP3deleted, or psiCHECK-RBSP3-point mutated vector or psiCHECK-RBSP3-full mutated vector containing the firefly luciferase reporter vector and $0.1 \mu \mathrm{g}$ of the control vector containing Renilla luciferase (pRL-TK) (Promega). HL60 cells were transfected by electroporation with $100 \mathrm{~nm}$ miR-100 negative control, $2.5 \mu \mathrm{g}$ of the psiCheck-control or psiCheckRBSP3 or psiCheck-RBSP3-deleted or psiCheck-RBSP3-point mutated vector, or psiCheck-RBSP3-full mutated vector containing firefly luciferase report vector and $2.5 \mu \mathrm{g}$ of the control vector containing Renilla luciferase, pRL-TK (Promega). Firefly and Renilla luciferase activities were measured consecutively at $24 \mathrm{~h}$ after transfection using Dual-luciferase assays (Promega) according to the manufacturer's instructions.

\section{Cell proliferation assays}

Cell proliferation was determined using the Cell Counting Kit-8 (CCK-8) as described previously (Hamamoto et al., 2004). Cells in a 24-well plate were transfected by electroporation with $100 \mathrm{~nm}$ miR-100 mimics, $200 \mathrm{~nm}$ miR-100 antisense, $100 \mathrm{~nm}$ siRBSP3 and the corresponding doses of miR NC, miR antisense NC and siRNA NC, respectively. After transfection, $1 \times 10^{4}$ cells per well were plated in 96-well plates, and the CCK-8 assay (Dojindo Molecular Technologies, Shanghai, China) was conducted after $24 \mathrm{~h}, 48 \mathrm{~h}, 72 \mathrm{~h}$ and $96 \mathrm{~h}$.

\section{Evaluation of myeloid differentiation}

Lentivirus RBSP3-infected cells and various cells transfected with $100 \mathrm{~nm}$ miR-100, $100 \mathrm{~nm}$ siRBSP3 and their negative controls by electroporation after $24 \mathrm{~h}$, were treated with $1 \mu \mathrm{M}$ ATRA (Sigma-Aldrich, Shanghai, China) and $10 \mathrm{~nm} \mathrm{1,25-}$ dihydroxy-vitamin D3 $\left(1,25 \mathrm{D}_{3}\right)$ (Sigma-Aldrich), respectively. Both granulocytic and monocytic differentiation was evaluated at day 4 after ATRA or $1,25 \mathrm{D}_{3}$ induction based on the cell morphology on Wright-Giemsa-stained slides. In all, 300 cells were counted to evaluate morphology. The expression of CD11b and CD15 for granulocytic differentiation and the expression of $\mathrm{CD} 11 \mathrm{~b}$ and CD14 for monocytic differentiation were detected on day 3 after induction by fluorescence activated cell sorter (FACS) analysis. For the FACS assay, the cells were stained with the following anti-human monoclonal antibodies: CD14-PE (eBioscience, San Diego, CA, USA), CD15-perCP (eBioscience), CD11b-APC (Invitrogen), which were measured using a FACSCaliber (BD Bioscience, San Jose, CA, USA). The data were analyzed using FACSDiva software (BD Biosciences). A minimum of 10000 events were collected for each sample.

\section{Western blot assay}

The cells were treated as indicated in the figures and lysed in RIPA buffer (Pierce, Rockford, IL, USA) with protease and phosphatase inhibitors (Roche, Beijing, China). The protein was separated in a $10 \%$ polyacrylamide gel and transferred to a methanol-activated PVDF membrane (Millipore, Beijing, China). The membrane was blocked for $2 \mathrm{~h}$ in Tris-buffered saline Tween-20 (TBST) containing 2\% bovine serum albumin and then probed with polyclonal rabbit anti-RBSP3 (Novus Biologicals, Littleton, CO, USA), antiphospho-Rb (Ser 807/811) (Cell Signaling Technology, Boston, MA, USA), monoclonal mouse anti-Rb (4H1) (Cell Signaling Technology), anti-E2F1 (clones KH20 and KH95, Upstate Millipore, Guangzhou, China) and polyclonal rabbit anti-glyceraldehyde-3-phosphate dehydrogenase antibodies (Proteintech Technology, Manchester, UK) or anti- $\beta$-actin antibody (Cell Signaling Technology) overnight at $4{ }^{\circ} \mathrm{C}$. After a $1 \mathrm{~h}$ incubation with anti-mouse (Pierce) or anti-rabbit (SigmaAldrich) HRP-conjugated secondary antibody, the protein level was detected using a luminal reagent (Millipore).

\section{Cell cycle assay}

The cells were transfected with $\mathrm{H}_{2} \mathrm{O}$ (denoted as mock), miR NC or miR-100 mimics by electroporation and plated in a 24-well plate. Nocodazole $(100 \mathrm{ng} / \mathrm{ml})$ was added to the cells $24 \mathrm{~h}$ after transfection. The cells were cultured for an additional $24 \mathrm{~h}$, collected and incubated with NP40/propidium iodide (PI) buffer and $0.5 \mu \mathrm{L}$ of RNase $(30 \mathrm{mg} / \mathrm{ml})$ for $30 \mathrm{~min}$ at $37^{\circ} \mathrm{C}$ before FACS analysis. PI-negative living cells were gated for the cell cycle analysis.

\section{Lentiviral construction and infection}

To overexpress RBSP3 in cells, lentiviral vector was constructed from. Briefly, full-length complementary DNA of RBSP3 (831 bp) were inserted to pLVX-PGK-IRES-ZsGreen lentiviral control vectors. pLVX-PGK-hRBSP3-IRES-ZsGreen or pLVX-PGK-IRES-ZsGreen and three packaged plasmids co-transfected into HEK-293T cells. Supernatant were harvested at 24 and $48 \mathrm{~h}$ after transfection passed through $0.45 \mu \mathrm{m}$ and concentrated. In all, $25 \mu$ lentivirus-RBSP3(lv-RBSP3) and $5 \mu 1$ lentivirus negative control (lv-NC) containing medium was mixed with equal volume $8 \mu \mathrm{g} / \mathrm{ml}$ polybrene (hexadimethrine bromide, Sigma, St Louis, MO, USA), and then used to infect HL60 cells. After $24 \mathrm{~h}$, target cells were washed twice with PBS and cultured in fresh medium until further analysis. 


\section{Conflict of interest}

The authors declare no conflict of interest.

\section{Acknowledgements}

We thank the following investigators and hospitals that provided samples for the analysis: Dr Hai-Xia Guo at the Second Affiliated Hospital of Sun Yat-sen University; Li-Bing Huang at the First Affiliated Hospital of Sun Yat-sen University; This work was supported by National Science and Technology Department (2011CBA01105, 2011CB811301 and 2009ZX09103-641) and the funds from National Natural
Science Foundation of China (No 30872784 and 81070440), as well as supported by 'the Fundamental Research Funds for the Central Universities'. We thank Nature Publishing Group Language Editing, LLC for editing the text of the manuscript.

Author contribution: YSZ and HZ contributed equally to this work, performing experiments, analyzing the data, and writing the manuscript; XJZ, DDF CWZ and KYL performed and analyzed western blot and qRT-PCR data; XQL and XL provided patient samples and clinical data and designed the experiments; HZ, LHQ and PZ analyzed the data and edited the manuscript; YQC designed experiments and edited the manuscript. All authors critically reviewed the manuscript.

\section{References}

Anedchenko EA, Dmitriev AA, Krasnov GS. (2008). Down-regulation of RBSP3/CTDSPL, NPRL2/G21, RASSF1A, ITGA9, HYAL1 and HYAL2 genes in non-small cell lung cancer. Mol Biol (Mosk) 42: 965-976.

Bartek J, Bartkova J, Lukas J. (1996). The retinoblastoma protein pathway and the restriction point. Curr Opin Cell Biol 8: 805-814.

Bartek J, Bartkova J, Lukas J. (1997). The retinoblastoma protein pathway in cell cycle control and cancer. Exp Cell Res 237: 1-6.

Bartel DP. (2004). MicroRNAs: genomics, biogenesis, mechanism, and function. Cell 116: 281-297.

Bousquet M, Quelen C, Rosati R, Mansat-De Mas V, Starza RL, Bastard C et al. (2008). Myeloid cell differentiation arrest by miR$125 \mathrm{~b}-1$ in myelodysplasic syndrome and acute myeloid leukemia with the t(2;11)(p21;q23) translocation. $J$ Exp Med 205: 2499-2506.

Careccia S, Mainardi S, Pelosi A, Gurtner A, Diverio D, Riccioni R et al. (2009). Restricted signature of miRNAs distinguishes APL blasts from normal promyelocytes. Oncogene 28: 4034-4040.

Chen CZ. (2005). MicroRNAs as oncogenes and tumor suppressors. New Engl J Med 353: 1768-1771.

Chen PL, Scully P, Shew JY, Wang JY, Lee WH. (1989). Phosphorylation of the retinoblastoma gene product is modulated during the cell cycle and cellular differentiation. Cell 58: 1193-1198.

Collins SJ, Robertson KA, Mueller L. (1990). Retinoic acid-induced granulocytic differentiation of HL-60 myeloid leukemia cells is mediated directly through the retinoic acid receptor (RAR-alpha). Mol Cell Biol 10: 2154-2163.

Dixon-McIver A, East P, Mein CA, Cazier JB, Molloy G, Chaplin T et al. (2008). Distinctive patterns of microRNA expression associated with karyotype in acute myeloid leukemia. PLoS One 3: e2141.

Esquela-Kerscher A, Slack FJ. (2006). Oncomirs - microRNAs with a role in cancer. Nat Rev Cancer 6: 259-269.

Estey E, Döhner H. (2006). Acute myeloid leukemia. Lancet 368: 1894-1907.

Estey E. (2007). Acute myeloid leukemia and myelodysplastic syndromes in older patients. J Clin Oncol 25: 1908-1915.

Farag SS, Ruppert AS, Mrózek K, Mayer RJ, Stone RM, Carroll AJ et al. (2005). Outcome of induction and postremission therapy in younger adults with acute myeloid leukemia with normal karyotype: a Cancer and Leukemia Group B study. J Clin Oncol 23: 482-493.

Fazi F, Rosa A, Fatica A, Gelmetti V, De Marchis ML, Nervi C et al. (2005). A mini-circuitry comprising microRNA-223 and transcription factors NFI-A and C/EBPa regulates human granulopoiesis. Cell 123: 819-831.

Fontana L, Pelosi E, Greco P, Racanicchi S, Testa U, Liuzzi F et al. (2007). MicroRNAs 17-5p-20a-106a control monocytopoiesis through AML1 targeting and M-CSF receptor upregulation. Nat Cell Biol 9: 775-787.
Garzon R, Heaphy CE, Havelange V, Fabbri M, Volinia S, Tsao T et al. (2009). MicroRNA 29b functions in acute myeloid leukemia. Blood 114: 5331-5341.

Ghosh A, Ghosh S, Maiti GP, Sabbir MG, Zabarovsky ER, Roy A et al. (2010). Frequent alterations of the candidate genes hMLH1, ITGA9 and RBSP3 in early dysplastic lesions of head and neck: clinical and prognostic significance. Cancer Sci 101: $1511-1520$.

Guo XB, Guo L, Ji J, Zhang JN, Zhang J, Chen XH et al. (2010). MiRNA-331-3p directly targets E2F1 and induces growth arrest in human gastric cancer. Biochem Biophys Res Commun 398: 1-6.

Hall M, Peters G. (1996). Genetic alterations of cyclins, cyclindependent kinases, and Cdk inhibitors in human cancer. Adv Cancer Res 68: 67-108.

Hamamoto R, Furukawa Y, Morita M, Iimura Y, Silva FP, Li M et al. (2004). SMYD3 encodes a histone methyltransferase involved in the proliferation of cancer cells. Nat Cell Biol 6: 731-740.

Han YC, Park CY, Bhagat G, Zhang J, Wang Y, Fan J et al. (2010). MicroRNA-29a induces aberrant self-renewal capacity in hematopoietic progenitors, biased myeloid development, and acute myeloid leukemia. J Exp Med 207: 475-489.

Ji Y, Studzinski GP. (2004). Retinoblastoma protein and CCAAT/ enhancer-binding protein beta are required for 1,25-dihydroxyvitamin D3-induced monocytic differentiation of HL60 cells. Cancer Res 64: 370-377.

Jiang JM, Lee EJ, Gusev Y, Schmittgen TD. (2005). Real-time expression profiling of microRNA precursors in human cancer cell lines. Nucleic Acids Res 33: 5394-5403.

Jongen-Lavrencic M, Sun SM, Dijkstra MK, Valk PJM, Löwenberg B. (2008). MicroRNA expression profiling in relation to the genetic heterogeneity of acute myeloid leukemia. Blood 111: 5078-5085.

Kashuba VI, Li J, Wang F, Senchenko VN, Protopopov A, Malyukova A et al. (2004). RBSP3 (HYA22) is a tumor suppressor gene implicated in major epithelial malignancies. Proc Natl Acad Sci USA 101: 4906-4911.

Kashuba VI, Pavlova TV, Grigorieva EV, Kutsenko A, Yenamandra SP, Li J et al. (2009). High mutability of the tumor suppressor genes RASSFland RBSP3 (CTDSPL) in cancer. PLoS One 4: e5231.

Lee KH, Chen YL, Yeh SD, Hsiao M, Lin JT, Goan YG et al. (2009). MicroRNA-330 acts as tumor suppressor and induces apoptosis of prostate cancer cells through E2F1-mediated suppression of Akt phosphorylation. Oncogene 28: 3360-3370.

Leite KR, Sousa-Canavez JM, Reis ST, Tomiyama AH, CamaraLopes LH, Sañudo A et al. (2009). Change in expression of miRlet7c, miR-100, and miR-218 from high grade localized prostate cancer to metastasis. Urol Oncol 29: 265-269.

Li Z, Lu J, Sun M, Mi S, Zhang H, Luo RT et al. (2008). Distinct microRNA expression profiles in acute myeloid leukemia with common translocations. Proc Natl Acad Sci USA 105: 15535-15540. 
Lim LP, Lau NC, Garrett-Engele P, Grimson A, Schelter JM, Castle J et al. (2005). Microarray analysis shows that some microRNAs downregulate large numbers of target mRNAs. Nature 433: 769-773.

Lin RJ, Lin YC, Yu AL. (2010). miR-149* induces apoptosis by inhibiting Akt1 and E2F1 in human cancer cells. Mol Carcinog 49: 719-727.

Liu S, Wu LC, Pang J, Santhanam R, Schwind S, Wu YZ et al. (2010). $\mathrm{Spl} / \mathrm{NFkappaB} / \mathrm{HDAC} / \mathrm{miR}-29 \mathrm{~b}$ regulatory network in KIT-driven myeloid leukemia. Cancer Cell 17: 333-347.

Lowenberg B, Downing JR, Burnett A. (1999). Acute myeloid leukemia. $N$ Engl J Med 341: 1051-1062.

Nagaraja AK, Creighton CJ, Yu Z, Zhu H, Gunaratne PH, Reid JG et al. (2010). A link between mir-100 and FRAP1/mTOR in clear cell ovarian cancer. Mol Endocrinol 24: 447-463.

Pigazzi M, Manara E, Baron E, Basso G. (2009). MiR-34b targets cyclic AMP-responsive element binding protein in acute myeloid leukemia. Cancer Res 69: 2471-2478.

Pulikkan JA, Dengler V, Peramangalam PS, Peer Zada AA, Müller-Tidow C, Bohlander SK et al. (2010). Cell-cycle regulator E2F1 and microRNA-223 comprise an autoregulatory negative feedback loop in acute myeloid leukemia. Blood 115: 1768-1778.

Rosa A, Ballarino M, Sorrentino A, Sthandier O, De Angelis FG, Marchioni $\mathrm{M}$ et al. (2007). The interplay between the master transcription factor PU.1 and miR-424 regulates human monocyte/ macrophage differentiation. Proc Natl Acad Sci USA 104: 19849-19854.

Senchenko VN, Anedchenko EA, Kondratieva TT, Krasnov GS, Dmitriev AA, Zabarovska VI et al. (2010). Simultaneous downregulation of tumor suppressor genes RBSP3/CTDSPL, NPRL2/ G21 and RASSF1A in primary non-small cell lung cancer. BMC Cancer 10: 75 .

Sherr CJ. (1996). Cancer cell cycles. Science 274: 1672-1677.
Shi W, Alajez NM, Bastianutto C, Hui AB, Mocanu JD, Ito E et al. (2010). Significance of Plk1 regulation by miR-100 in human nasopharyngeal cancer. Int $J$ Cancer 126: 2036-2048.

Sinha S, Singh RK, Alam N, Roy A, Roychoudhury S, Panda CK. (2008). Frequent alterations of hMLH1 and RBSP3/HYA22 at chromosomal 3p22.3 region in early and late-onset breast carcinoma: clinical and prognostic significance. Cancer Sci 99: 1984-1991.

Strauss M, Lukas J, Bartek J. (1995). Unrestricted cell cycling and cancer. Nat Med 1: 1245-1246.

Strom DK, Cleveland JL, Chellappan S, Nip J, Hiebert SW. (1998). E2F-1 and E2F-3 are functionally distinct in their ability to promote myeloid cell cycle progression and block granulocyte differentiation. Cell Growth Differ 9: 59-69.

Varnholt H, Drebber U, Schulze F, Wedemeyer I, Schirmacher P, Dienes HP et al. (2008). MicroRNA gene expression profile of hepatitis $\mathrm{C}$ virus-associated hepatocellular carcinoma. Hepatology 47: $1223-1232$

Wang J, Zhao Y, Kauss MA, Spindel S, Lian H. (2009). Akt regulates vitamin D3-induced leukemia cell functional differentiation via Raf/MEK/ERK MAPK signaling. Eur J Cell Biol 88: 103-115.

Weinberg RA. (1995). The retinoblastoma protein and cell cycle control. Cell 81: 323-330.

Zhang H, Luo XQ, Zhang P, Huang LB, Zheng YS, Wu J et al. (2009). MicroRNA patterns associated with clinical prognostic parameters and CNS relapse prediction in pediatric acute leukemia. PLoS One 4: e7826.

(c)

OMERIGHTS RESE

This work is licensed under the Creative Commons Attribution-NonCommercial-No Derivative

Works 3.0 Unported License. To view a copy of this license, visit http://creativecommons.org/licenses/by-nc-nd/3.0/

Supplementary Information accompanies the paper on the Oncogene website (http://www.nature.com/onc) 